\title{
In vitro degradation of glycine/DL-lactic acid copolymers
}

\author{
J. Helder, P. J. Dijkstra, and J. Feijen* \\ Department of Chemical Technology, Twente University, PO Box 217, 7500 AE, Enschede, \\ The Netherlands
}

The in vitro degradation of glycine-DL-lactic acid copolymers was studied as a function of the composition. These polydepsipeptides were prepared by ring-opening copolymerization of 6-methyl-2,5-morpholinedione and DL-lactide. The degradation of discs of the copolymers was performed in a phosphate buffer at $\mathrm{pH} 7.4$ and $37^{\circ} \mathrm{C}$. The decrease in molecular weight and weight was determined until complete weight loss had occurred. Poly(DL-lactide) was used as a reference material. All (co)polymers show an immediate decrease in molecular weight, whereas the weight remains almost unchanged during a longer period of time. Decrease in weight started earlier as the glycine content of the copolymer increased. The lactic acid content of the residual material increased during the weight loss showing a higher solubility of polymer fragments with a relatively high content of glycine residues. From the hydrolysis constants it was concluded that the degradation was best described by hydrolysis of ester bonds via a bulk erosion process, autocatalyzed by the generated carboxylic acid end groups. The rate constants varied from $4-7 \times 10^{-2}\left(\right.$ day $\left.^{-1}\right)$ for all (co)polymers. All (co)polymers show an increase in the molecular weight distribution upon weight loss.

\section{INTRODUCTION}

During the last few decades the use of synthetic polymers for medical devices has rapidly expanded. Currently the great potential of biodegradable polymers for application in sutures, bone plates, and other surgical fixation devices and especially drug delivery systems is widely recognized. ${ }^{1}$ Biodegradable polymers should have labile bonds, which can be cleaved in the body forming nontoxic degradation products. Several aliphatic polyesters $^{2-4}$ and poly ( $\alpha$-amino acids) $)^{3,5}$ meet these requirements.

The extensive literature concerning the degradation of polyesters has been reviewed by Holland et al. ${ }^{2}$ After penetration of water into the polymer matrix, degradation starts through a bulk hydrolysis of ester bonds and the molecular weight decreases. Weight loss ensues when the molecular weight of the polymer chains has sufficiently decreased. ${ }^{6-11}$ In crystalline polymers like poly(glycolic acid) (PGA), poly(L-lactic acid) (PLLA), and poly $(\varepsilon$-caprolactone) (PCL) degradation first occurs in the amorphous regions and later in the crystalline domains. ${ }^{72-14}$ As a result during the initial stages of degradation the crystallinity increases. The period required for

Journal of Biomedical Materials Research, Vol. 24, 1005-1020 (1990)

(C) 1990 John Wiley \& Sons, Inc.

CCC 0021-9304/90/081005-16\$04.00 
complete degradation depends on the type of polymer, the crystallinity, the initial molecular weight of the samples, and the glass transition temperature. Although some enzymes were found to affect the degradation of $\mathrm{PGA}^{16}$ and PLLA $^{17}$ in vitro, an enzymatic contribution to the initial stages of degradation of polyesters has not been observed in vivo. ${ }^{18,19}$ Most authors come to the conclusion that enzymes do not play a role in the initial degradation process of polyesters in the glassy state. ${ }^{2,20,21}$ However, enzymes are involved in the subsequent degradation of hydrolysis products formed during the initial degradation of polymers. ${ }^{20,21}$

Only a few studies about the degradation of copolymers containing both ester and amide groups were reported. ${ }^{22,23}$ More recently Kaetsu et al. ${ }^{24-26}$ studied the in vivo degradation of several sequential polydepsipeptides. Melt pressed films of polydepsipeptides were absorbed after several weeks' implantation in rats ${ }^{24,25}$ and the polydepsipeptides were more readily degraded than the corresponding poly ( $\alpha$-amino acids) ${ }^{26}$ Previously we showed that the in vivo and in vitro degradation behavior of some glycine/ DL-lactic acid copolymers and poly(DL-lactic acid) appeared comparable. ${ }^{27}$

In this paper we present the results of studies on the in vitro degradation of films of nonalternating glycine/DL-lactic acid copolymers (copoly(gly-DLlac)). The degradation was followed by measuring the decrease of the molecular weight, the weight loss, and the changes in polymer composition as a function of time. The degradation of the glycine/DL-lactic acid copolymers was compared with that of poly(DL-lactic acid) (PDLA).

\section{MATERIALS AND METHODS}

\section{Materials}

Copolymers were synthesized by ring-opening polymerization of 6-methylmorpholine-2,5-dione (cyclo(Gly-DL-Lac)) and DL-lactide in the melt at $135^{\circ} \mathrm{C}$ as described previously. ${ }^{28}$ Molar percentages of DL-lactide in the feed of 50, 60, 70, 75, 80, and 90 were used. A low-molecular-weight PDLA sample (code 100) was a gift from CCA Biochem, Gorinchem, The Netherlands. A high-molecular-weight PDLA sample (code DL) was prepared using the procedure applied for the synthesis of the copolymers. ${ }^{28}$

\section{Preparation of polymer discs}

Films were made by casting solutions of the copolymers in tetrahydrofuran (THF, $15 \% \mathrm{w} / \mathrm{v}$ ) onto glass surfaces, which were previously treated with a $30 \% \mathrm{v} / \mathrm{v}$ solution of dichlorodimethylsilane in toluene. The THF was slowly evaporated in air at room temperature for at least 3 days and subsequently at $40^{\circ} \mathrm{C}$ for 24 hours at reduced pressure $(0.01 \mathrm{~mm} \mathrm{Hg})$. The films were then immersed in demineralized water for $2 \mathrm{~h}$ to exchange residual solvent. After removal from the water, the films were dried over $\mathrm{P}_{2} \mathrm{O}_{5}$ at re- 
duced pressure $(0.01 \mathrm{~mm} \mathrm{Hg})$ for $18 \mathrm{~h}$ and were then cut into discs with a diameter of $12 \mathrm{~mm}$. Subsequently, the discs were dried to constant weight at reduced pressure $(0.01 \mathrm{~mm} \mathrm{Hg})$ at $40^{\circ} \mathrm{C}$ for at least $18 \mathrm{~h}$. The average weight of 40 discs of each series was $52 \pm 12,52 \pm 7,52 \pm 7,58 \pm 13$, $56 \pm 4,59 \pm 14$, and $52 \pm 6 \mathrm{mg}$ for (co)polymers 50 to 100 , respectively, and $48 \pm 3 \mathrm{mg}$ for polymer DL. The average thicknesses of the 40 discs were $530 \pm 100,470 \pm 40,460 \pm 70,460 \pm 100,420 \pm 40,430 \pm 120$, and $380 \pm 40 \mu \mathrm{m}$ for (co)polymers 50 to 100 , respectively, and $350 \pm 20 \mu \mathrm{m}$ for polymer DL.

\section{Degradation studies}

For each (co)polymer 40 discs were used to follow the degradation as a function of time. Each disc was weighed and placed in a vial containing $5 \mathrm{~mL}$ of an aqueous buffer solution (0.1M Na $\left.\mathrm{HPO}_{4} / \mathrm{KH}_{2} \mathrm{PO}_{4}, \mathrm{pH} 7.4\right)$ with $0.03 \mathrm{wt} \%$ sodium azide to prevent bacterial growth. The vials were placed in a thermostatically controlled water bath at $37 \pm 2^{\circ} \mathrm{C}$. For each (co)polymer one disc was removed after a predetermined immersion time and the $\mathrm{pH}$ of the remaining buffer solution was measured. When the $\mathrm{pH}$ was lower than 7.3 the buffer solutions in the remaining vials containing discs of the same (co)polymer were replaced. Using this procedure the buffer solutions never reached a $\mathrm{pH}$ value lower than 6.9 even when the weight loss of the polymer samples was considerable. After removal from the buffer solution the discs were washed with distilled water and dried to constant weight over $\mathrm{P}_{2} \mathrm{O}_{5}$ at reduced pressure $(0.01 \mathrm{~mm} \mathrm{Hg})$ for at least $48 \mathrm{~h}$.

The degradation of the (co)polymers was followed by measuring the weight and the apparent molecular weight of the residual material as a function of time. The weight loss of each disc was determined by comparing the dry weight of the degraded (co)polymer with the initial weight.

The molecular weight distributions, apparent weight average $\left(M_{w, a p p}\right)$ and number average molecular weight $\left(\mathrm{M}_{n, \text { app }}\right)$ of the undissolved (co)polymer material were determined using high-performance Gel Permeation Chomatography (GPC). The GPC unit consisted of a Waters model $6000 \mathrm{~A}$ pump and a Waters U6K injector, four Waters mStyragel $\left(10^{5}, 10^{4}, 10^{3}\right.$, and $500 \AA$ in pore size) columns in series and a Waters R401 differential refractometer. Elution was performed at $25^{\circ} \mathrm{C}$ with a flow rate of $2.0 \mathrm{~mL} / \mathrm{min}$ using THF as eluent. The columns were calibrated with polystyrene standards having narrow molecular weight distributions. It has to be realized that the $M_{n, \text { app }}$ and $M_{w, \text { app }}$ values measured depend on the composition of the molecules. During the degradation the molecular weight of the polymers is changing and the chemical composition may change also.

To obtain a better estimation of the real values of the initial molecular weights of the copolymers $M_{n \text {, calc }}$ values were determined. The $M_{n, \text { calc }}$ value of, e.g., copolymer 75 was obtained by multiplying the $M_{n, \text { app }}$ value of copolymer 75 with the ratio $\mathrm{M}_{n}{ }^{*} / \mathrm{M}_{\mathrm{n} \text {, app }}{ }^{*}$ determined for a copolymer with 
the same composition but a different molecular weight. the $\mathrm{M}_{n}^{*}$ value was measured by membrane osmometry and the $\mathrm{M}_{\mathrm{r} \text {, app }}{ }^{*}$ value was measured by GPC.

The overall composition of partly degraded samples was determined by ${ }^{1} \mathrm{H}-\mathrm{NMR}$ spectroscopy. The spectra were recorded on a Nicolet $200 \mathrm{MHz}$ NMR apparatus using $\mathrm{CDCl}_{3}$ as a solvent and tetramethylsilane (TMS) as an internal reference. The copolymers gave distinct signals for the glycine methylene protons at $\delta 4.0$ and for the lactic acid methine protons at $\delta 5.1$, respectively. The composition was calculated from the methylene and methine proton integrations.

To investigate the microstructure of the (co)polymer discs the cross sections and surfaces were examined by scanning electron microscopy (SEM) with a JEOL JSM $35 \mathrm{CF}$ scanning electron microscope. The samples were coated with a charge conducting layer of gold using a Balzer sputter unit.

\section{RESULTS}

\section{Degradation profiles}

Table I shows that the initial molecular weights $\left(\mathrm{M}_{n, \text { calc }}\right)$ of the copolymers and polymer 100 are in the same order of magnitude. The apparent weightaverage molecular weight $\left(M_{w, a p p}\right)$, number-average molecular weight $\left(M_{n, \text { app }}\right)$, and the residual weight $(\% \mathrm{wt})$ of the (co)polymer samples as a function of immersion time in buffer solution are shown in Figure 1. This figure shows that for each (co)polymer the decrease of the molecular weight starts immediately after immersion of the film in the buffer solution. After the start of weight loss the $M_{w, \text { app }}$ and $M_{n \text {, app }}$ values of the (co)polymers remain almost constant (copolymers 50-80) or are even higher ((co)polymers 90, 100, and $\mathrm{DL})$ than the values of the samples measured just before weight loss.

TABLE I

Composition and Initial Molecular Weights of the (Co)polymers

\begin{tabular}{|c|c|c|c|c|c|}
\hline \multirow{2}{*}{$\begin{array}{c}\text { Sample } \\
\text { Code }\end{array}$} & \multicolumn{2}{|c|}{ Mol Fraction of DL-Lactide } & \multirow{2}{*}{$\begin{array}{c}M_{\mathrm{n}, \mathrm{app}}^{\mathrm{a}} \\
\left(\times 10^{-4}\right)\end{array}$} & \multirow{2}{*}{$\begin{array}{c}M_{n, \text { calc }}{ }^{\mathrm{b}} \\
\left(\times 10^{-4}\right)\end{array}$} & \multirow{2}{*}{$\begin{array}{l}M_{w, \text { app }}{ }^{a} \\
\left(\times 10^{-4}\right)\end{array}$} \\
\hline & In the Feed & In the Copolymer & & & \\
\hline 50 & 0.50 & $0.55 \pm 0.03$ & 0.5 & 3.9 & 1.5 \\
\hline 60 & 0.60 & $0.64 \pm 0.03$ & 1.1 & 2.7 & 3.0 \\
\hline 70 & 0.70 & $0.74 \pm 0.03$ & 2.0 & 3.2 & 4.3 \\
\hline 75 & 0.75 & $0.78 \pm 0.03$ & 2.9 & 4.2 & 5.4 \\
\hline 80 & 0.80 & $0.82 \pm 0.03$ & 3.8 & 6.5 & 6.7 \\
\hline 90 & 0.90 & $0.92 \pm 0.03$ & 4.8 & 4.0 & 9.7 \\
\hline 100 & 1.00 & 1.00 & 3.8 & 3.2 & 8.2 \\
\hline DL & 1.00 & 1.00 & 16.7 & 14.2 & 42.6 \\
\hline
\end{tabular}

${ }^{\mathrm{a} A p p a r e n t}$ molecular weights were measured by GPC.

${ }^{b}$ The $M_{n}$ values of these samples were calculated (see degradation studies). 

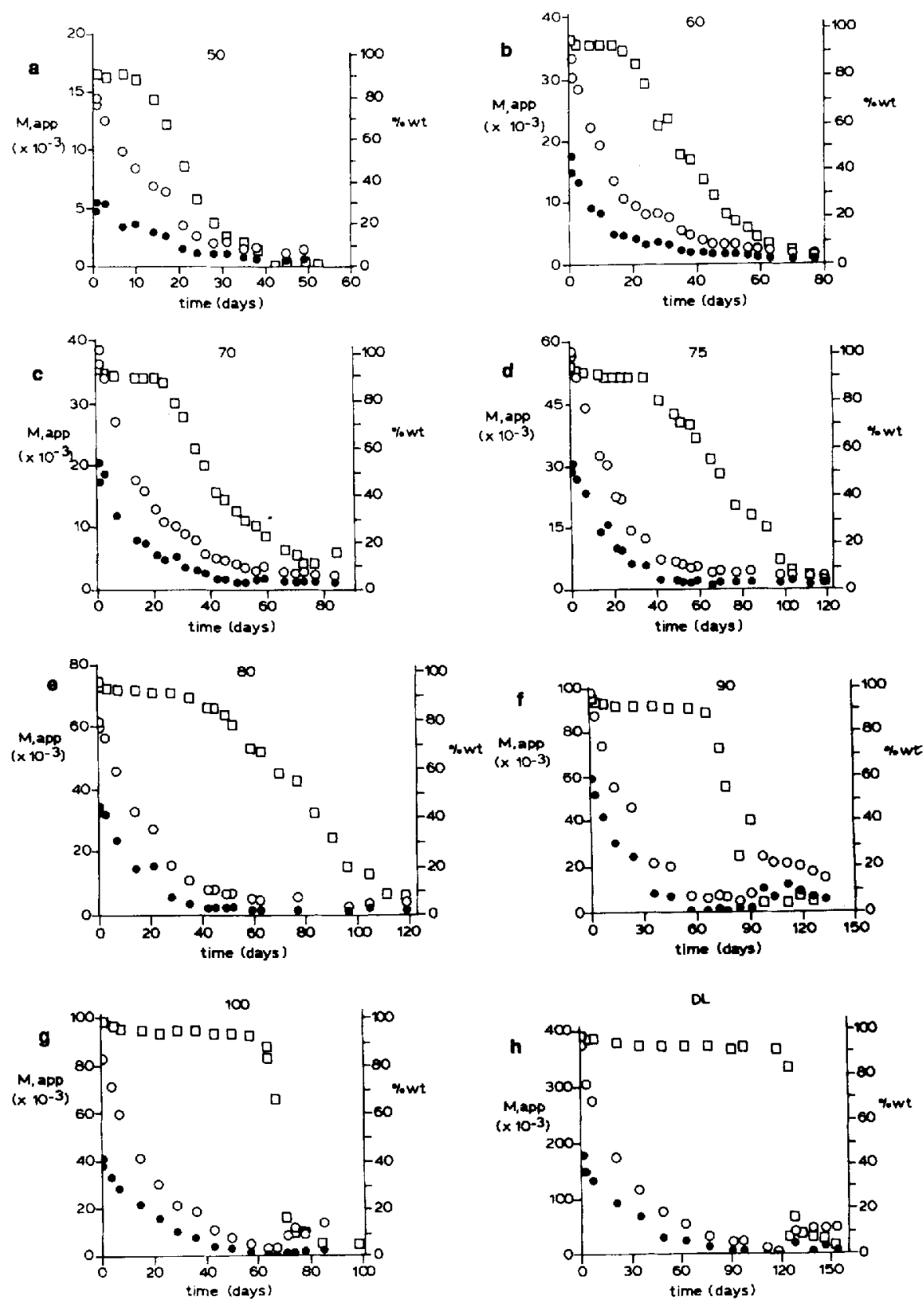

Figure 1. $M_{w, \text { app }}(0), M_{n \text {, app }}(\bullet)$, and residual weight ( $\square$ ) of copolymer 50 (a), 60 (b), 70 (c), 75 (d), $80(\mathrm{e}), 90(\mathrm{f}), 100(\mathrm{~g})$, and DL (h) as a function of time.

All (co)polymers show a similar pattern for the residual weight as a function of immersion time. During the first 3 days a fast, but small decrease of the weight is observed. Thereafter the weight of the samples remains 
almost constant for a longer period. Finally a rapid decrease in weight is seen. From Figure 1 it can be seen that the time-interval, where the weight of the polymers remains almost constant, increases with increasing copolymer lactic acid content. The rates of weight loss from 90 to $20 \%$ residual weight have been plotted as a function of the mol fraction DL-lactide in the (co)polymers in Figure 2. A minimum in the rate of weight loss is observed for (co)polymers 75 and 80 . Both increasing lactic acid or glycine contents of the copolymers increases the rate of weight loss. After the beginning of weight loss the discs started to fragment.

\section{Molecular weight distributions}

The changes in molecular weight distributions for copolymers 80 and 100 as a function of immersion time are shown in Figures 3 and 4, respectively. Initially the molecular weight distribution of copolymer 80 is broadened. In later stages of the degradation, the distribution is narrowed by dissolution of low-molecular-weight fractions. The molecular weight distribution is continuously shifted to lower molecular weights. Copolymers 50, 60, 70, and 75 show a similar profile as copolymer 80 . The distribution of polymer 100 just after the start of weight loss shows two peaks. Copolymer 90 and polymer DL show similar molecular weight distribution patterns in time as found for polymer 100 .

\section{Compositional changes}

Table II represents the overall composition of copolymers $50,60,70$, and 75 after different degradation times. The data show that the lactic acid content

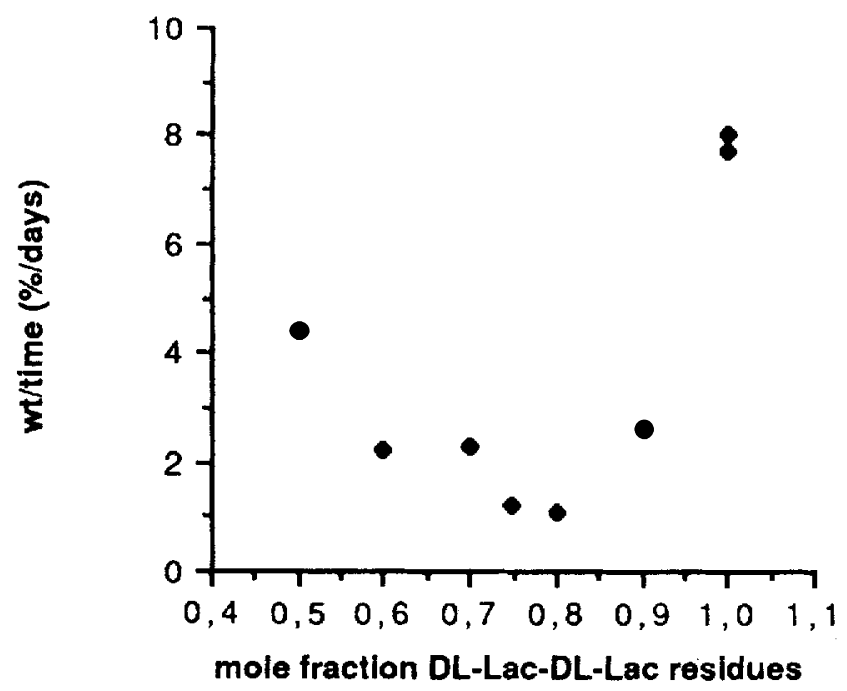

Figure 2. Rate of weight loss as a function of the mol fraction DL-lactide in the (co)polymers. 


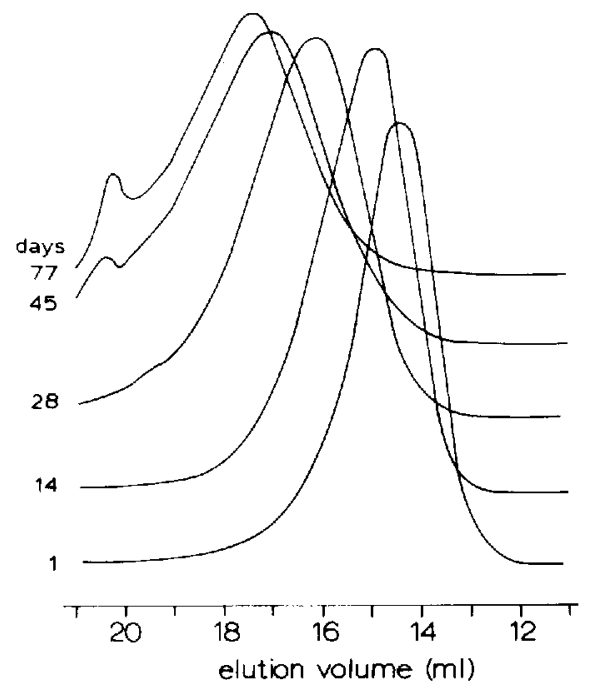

Figure 3. GPC of copolymer 80 after $1,14,28,45$, and 77 days immersion in buffer solution.

of the residual material increases after the start of weight loss. Furthermore, it can be observed that just before complete dissolution the remaining parts of the films still contain glycine residues.

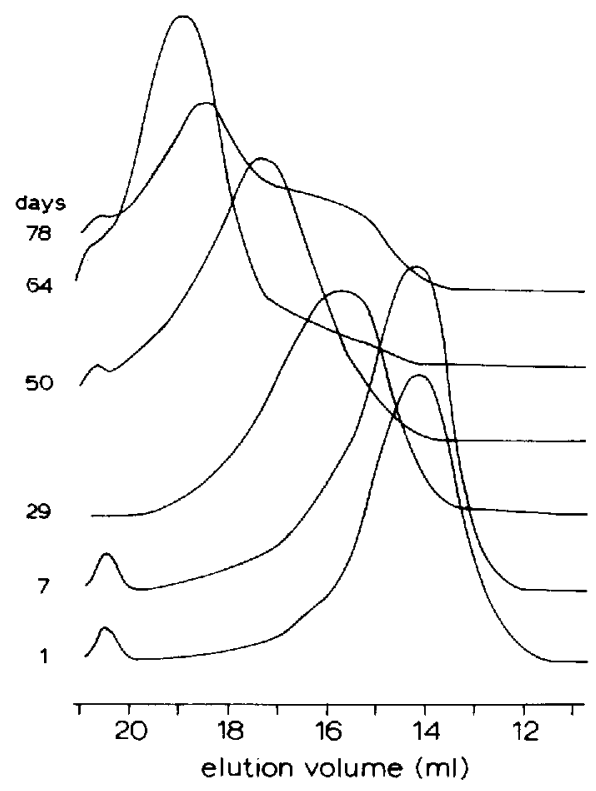

Figure 4. GPC of polymer DL after 1, 7, 29, 50, 64, and 78 days immersion in buffer solution. 
TABLE II

Composition and Residual Weight of the Copolymers 50, 60, 70, and 75 after Different Degradation Times

\begin{tabular}{|c|c|c|c|c|c|c|c|c|c|c|c|}
\hline \multicolumn{3}{|c|}{50} & \multicolumn{3}{|c|}{60} & \multicolumn{3}{|c|}{70} & \multicolumn{3}{|c|}{75} \\
\hline $\begin{array}{l}\text { Time } \\
\text { (days) }\end{array}$ & $F^{\mathbf{a}}$ & $\% \mathrm{wt}$ & $\begin{array}{c}\text { Time } \\
\text { (days) }\end{array}$ & $F^{\mathrm{a}}$ & $\% \mathrm{wt}$ & $\begin{array}{c}\text { Time } \\
\text { (days) }\end{array}$ & $F^{a}$ & $\%$ wt & $\begin{array}{l}\text { Time } \\
\text { (days) }\end{array}$ & $F^{a}$ & $\% \mathrm{wt}$ \\
\hline 0 & 77 & 100 & 0 & 83 & 100 & 0 & 87 & 100 & 0 & 89 & 100 \\
\hline 1 & 78 & 92 & 1 & 83 & 95 & 1 & 87 & 94 & 1 & 88 & 94 \\
\hline 7 & 77 & 91 & 7 & 83 & 92 & 7 & 86 & 91 & 7 & 89 & 92 \\
\hline 14 & 81 & 80 & 14 & 83 & 92 & 21 & 87 & 90 & 24 & 90 & 90 \\
\hline 21 & 87 & 48 & 31 & 86 & 62 & 38 & 92 & 54 & 59 & 91 & 64 \\
\hline 31 & 89 & 14 & 45 & 91 & 29 & 59 & 92 & 23 & & & \\
\hline 38 & 90 & 2 & 63 & 94 & 10 & 73 & 95 & 12 & & & \\
\hline
\end{tabular}

${ }^{\mathrm{a}} F$ is the percentage of lactic acid units in the copolymer.

\section{SEM analysis}

Scanning electron micrographs of cross sections of discs of copolymers 50 and 90 , which had been immersed in buffer solution for 1 day, are shown in Figures 5 and 6, respectively. These pictures are also representative examples for copolymers $60-80$ and polymers 100 and DL, respectively. Many small pores near the surfaces and a dense inner structure can be distinguished. Copolymer 50 as well as copolymers 60, 70, 75, and 80 (not shown)

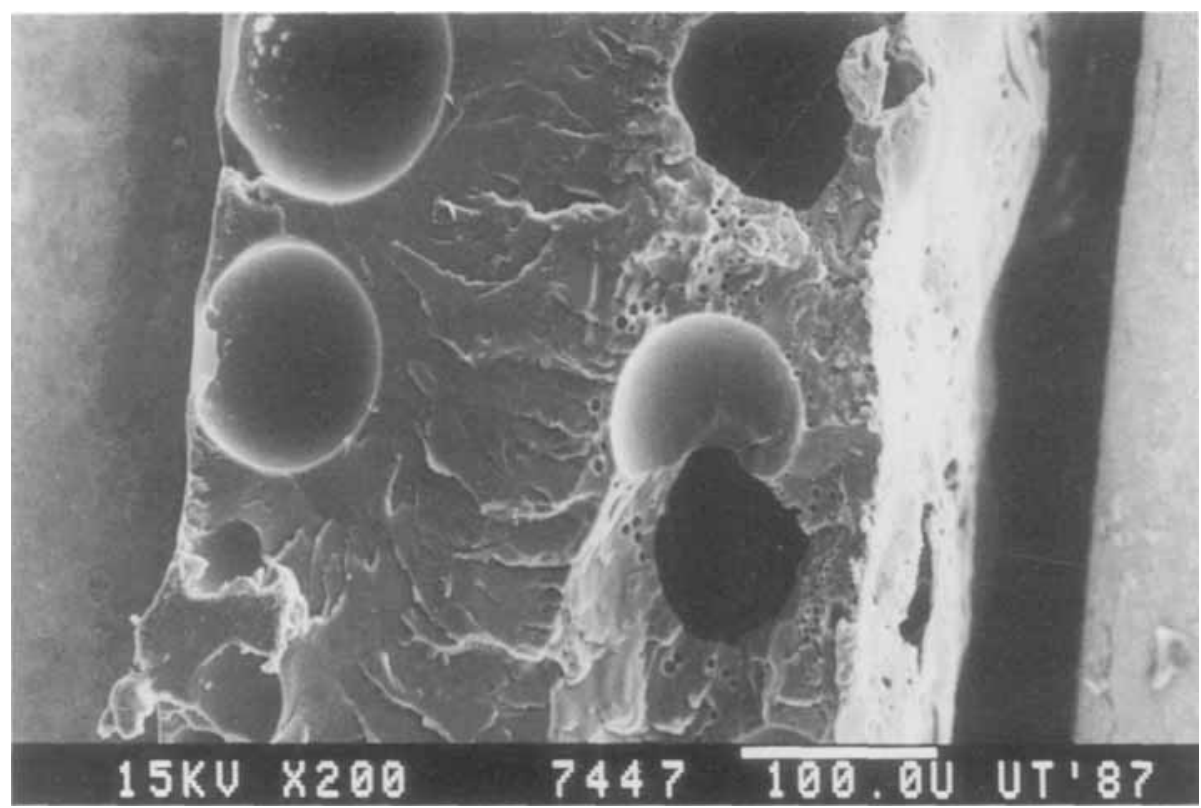

Figure 5. SEM micrograph of the cross section of a dried disc of copolymer 50 after 1 day immersion in buffer solution. 


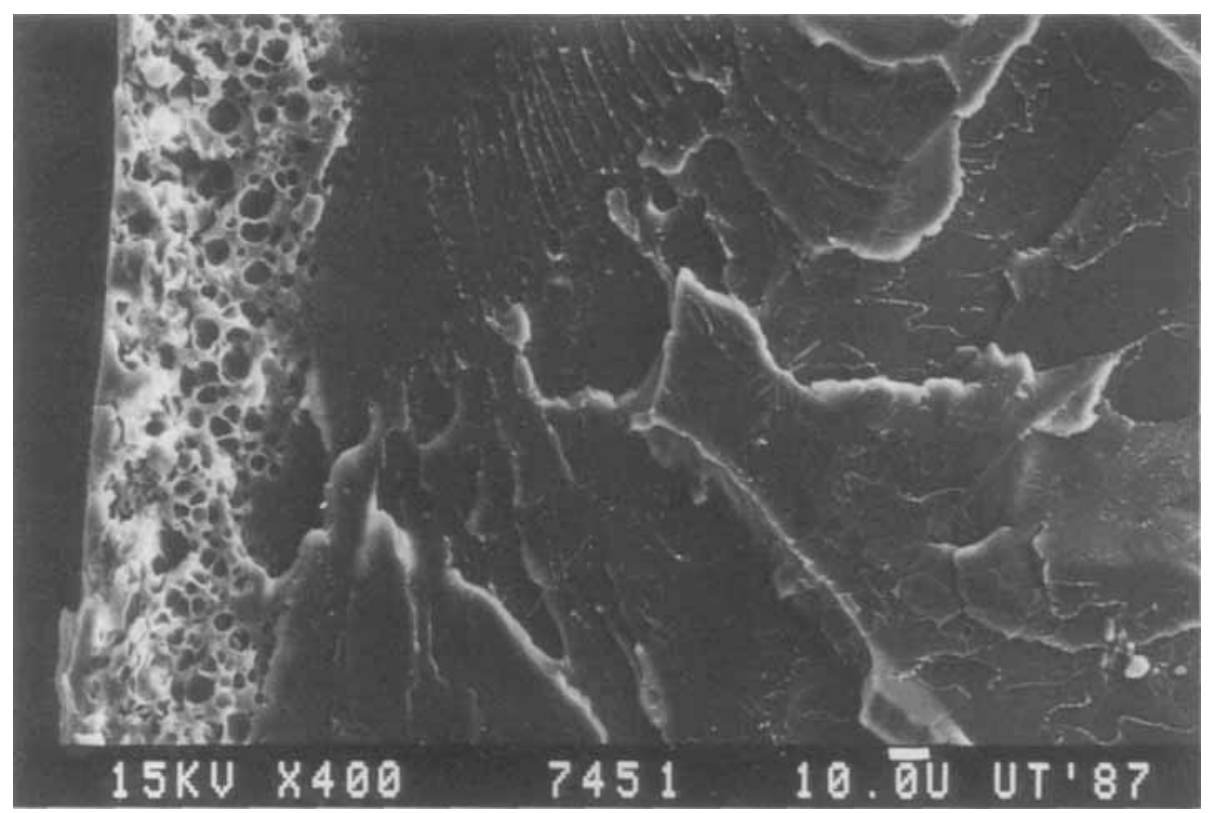

Figure 6. SEM micrograph of the cross section of a dried disc of copolymer 90 after 1 day immersion in buffer solution.

show voids of about $100 \mu \mathrm{m}$ diameter near the surfaces. These voids are not observed for (co)polymers 90,100 , and $\mathrm{DL}$, which have a dense inner structure and small pores near the surface. After longer immersion times the number of pores in the copolymer films had increased. This is illustrated by the SEM picture of a cross section of a disc of copolymer 50, which had been immersed in buffer solution for 7 days (Fig. 7). A similar behavior was seen for the other polymers after long immersion times.

\section{DISCUSSION}

The plots of the residual weight of the discs as a function of time all exhibit a period in which the weight remains constant while the molecular weight decreases (Fig. 1). This indicates that the degradation of the glycine/ DL-lactic acid copolymers and PDLA is a bulk erosion process. The immediate decrease of the molecular weight after immersion of the (co)polymer films indicates that water is able to penetrate rapidly into the film.

The glycine/DL-lactic acid copolymers may degrade via amide bond scission, ester bond scission or both. Generally polyamides are quite stable under physiological conditions. ${ }^{22}$ It has also been described that the principle mechanism of the in vivo degradation of poly(ester-amides) is the hydrolysis of the ester bonds. ${ }^{23}$ On the basis of these results we hypothesize that amide 


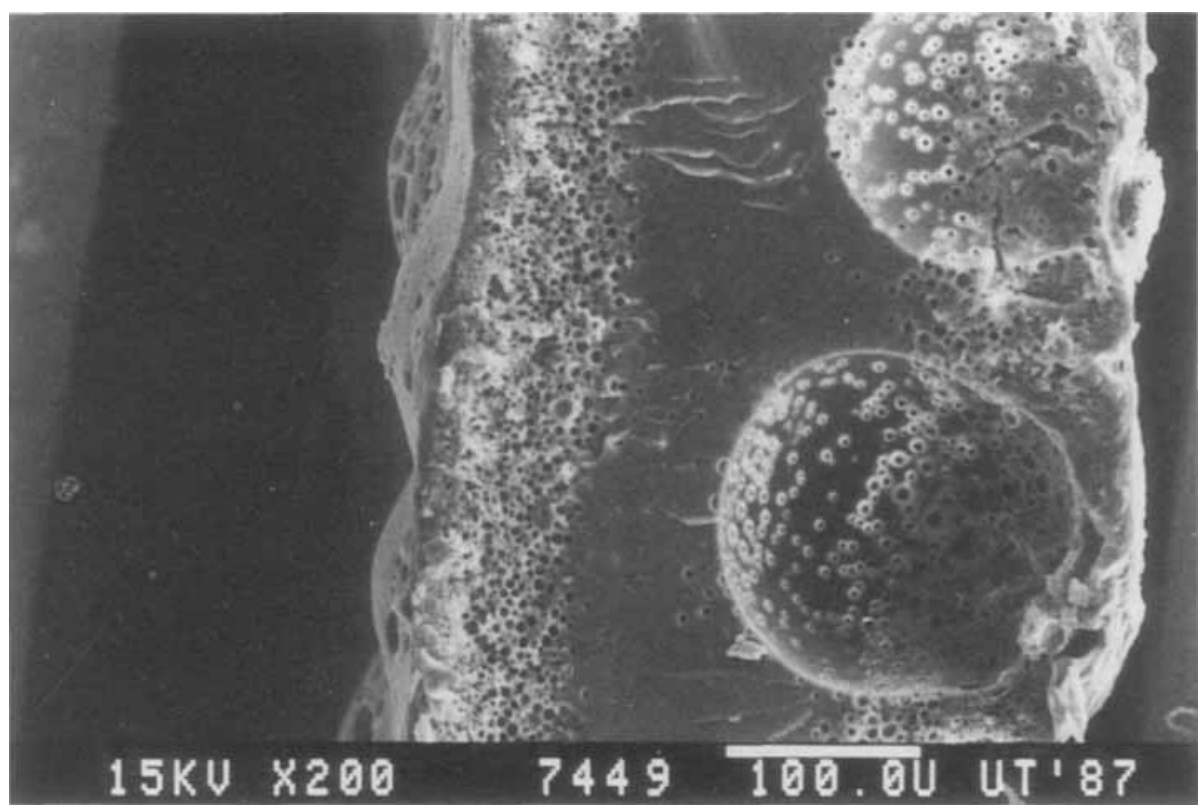

Figure 7. SEM micrograph of the cross section af a dried disc of copolymer 50 after 7 days immersion in buffer solution.

bond cleavage is less important for the degradation of the (co)polymers here described.

The mechanism of the hydrolysis reaction can be analyzed by determining the molecular weight and weight of the different (co)polymers as a function of time. Recently several investigators reported equations describing the hydrolysis of polyesters. $9,10,13$

Pitt and $\mathrm{Gu}^{9}$ derived two expressions, one for autocatalytic hydrolysis and one for uncatalyzed hydrolysis. For the hydrolysis autocatalyzed by the generated carboxylic end groups $(=\mathrm{COOH})$ the following equation pertains:

$$
d[\mathrm{COOH}] / d t=k_{\mathrm{I}}[\mathrm{COOH}] \text { [ester] [water] }
$$

Assuming [ester $]=[$ water $]=$ constant and $[\mathrm{COOH}]=1 / M_{\mathrm{n}}$ gives:

$$
\ln \left(M_{\mathrm{n}}\right)=\ln \left(M_{\mathrm{n}^{\circ}}\right)-k_{2} \cdot t
$$

in which: $M_{\mathrm{n}^{\circ}}=$ number average molecular weight at the start of the hydrolysis, $k_{2}=$ rate constant, and $t=$ time. The authors ${ }^{9}$ assume that the generated carboxyl acid end groups are not ionized in the hydrophobic bulk and catalyze the hydrolysis by hydrogen bonding to ester links. However, it can also be imagined that the carboxylic acid end groups are ionized and still catalyze the hydrolysis.

For uncatalyzed hydrolysis Eq. (3) applies:

$$
d[\mathrm{COOH}] / d t=k_{3}[\text { ester }][\text { water }]
$$


Provided the degree of polymerization is high, [ester] and [water] may be considered as constant during the initial stages of hydrolysis. Integration gives:

$$
1 / M_{\mathrm{n}}=1 / M_{\mathrm{n}^{\mathrm{o}}}+k_{4} \cdot t
$$

Mason et al. ${ }^{13}$ reported that Eq. (2) was valid for the description of the random chain scission of PDLA chains, disregarding changes in molecular weight distributions. They derived Eq. (2) by integration of Eq. (5):

$$
-d\left(M_{n}\right) / d t=-k \cdot M_{n}
$$

Kenley et al. ${ }^{10}$ studied the kinetics of the random chain scission of glycolic/ lactic acid copolymer using the kinetic model derived by Inokuti. ${ }^{29}$ However, Kenley et al. confounded the weight average degree of polymerization in the model of Inokuti for the number average degree of polymerization.

We have used the approach of Pitt and $\mathrm{Gu}^{9}$ to analyze the changes in $M_{\mathrm{n} \text {, app }}$ during degradation of the glycine/DL-lactic acid copolymers and PDLA before the start of weight loss. Measuring the $M_{n \text {, apparent }}$ and $M_{\mathrm{w} \text {, apparent }}$ values appeared one of the few ways to obtain information about the rate of degradation of the (co)polymers described in this study. As stated in the section Materials and Methods the $M_{n, \text { app }}$ and $M_{w, \text { app }}$ values do not give the actual molecular weights. However, as shown in Table I the apparent and calculated values only vary by a factor $<2$. The rate of degradation of the (co)polymers was determined during the period before weight loss occurs and in this period the molecular weight distribution $\left(M_{w, \text { app }} / M_{n, \text { app }}\right)$ and overall composition did not change. Using this methodology the calculated rates of degradation may not be absolute, but an impression of the order of magnitude is given. Finally, only copolymers which do not differ to a large extent in their compositions are compared.

Figure 8 shows a plot of $\ln \left(M_{\mathrm{n}, \text { app }}\right)$ versus immersion time for (co)polymers $50,70,80$, and $\mathrm{DL}$, according to autocatalytic hydrolysis (Eq. (2)). Figure 9 gives a plot of $1 / M_{n \text {, app }}$ versus the immersion time for the same (co)polymers based on uncatalyzed hydrolysis (Eq. (4)). In order to decide which mechanism is more appropriate the data of Figures 8 and 9 were compared by measuring the correlation coefficients (Table III). From Table III it appears that the changes in $M_{\mathrm{n} \text {, app }}$ of the glycine/DL-lactic acid copolymers in time are more consistent with an autocatalytic hydrolysis process.

The rate constants $k_{2}$ (Eq. (2)) for the different copolymers are in the same order of magnitude. These data confirm the earlier hypothesis that hydrolysis of the glycine/DL-lactic acid copolymers occurs mainly by ester bond scission.

Pitt et al. ${ }^{9}$ determined the rate constants for the autocatalytic degradation of melt-pressed films of several polyesters in buffer at $\mathrm{pH}$ 7.4. They found values of the rate constants of $1.8 \times 10^{-3}$ day $^{-1}$ for PCL and PLLA and $2.9 \times$ $10^{-2}$ day $^{-1}$ for a $3 / 7$ glycolic/L-lactic acid copolymer. The rate constants of the hydrolysis of glycine/DL-lactic acid copolymers $\left(5-7 \times 10^{-2}\right.$ day $\left.^{-1}\right)$ are higher probably due to the absence of crystallinity in the polydepsipeptides. This is supported by the finding that the hydrolysis constants of PDLA films with molecular weights of $3.2 \times 10^{4}$ and $14.2 \times 10^{4}$ were $4 \times$ $10^{-2}$ day $^{-1}$ and $5 \times 10^{-2}$ day $^{-1}$, respectively. 


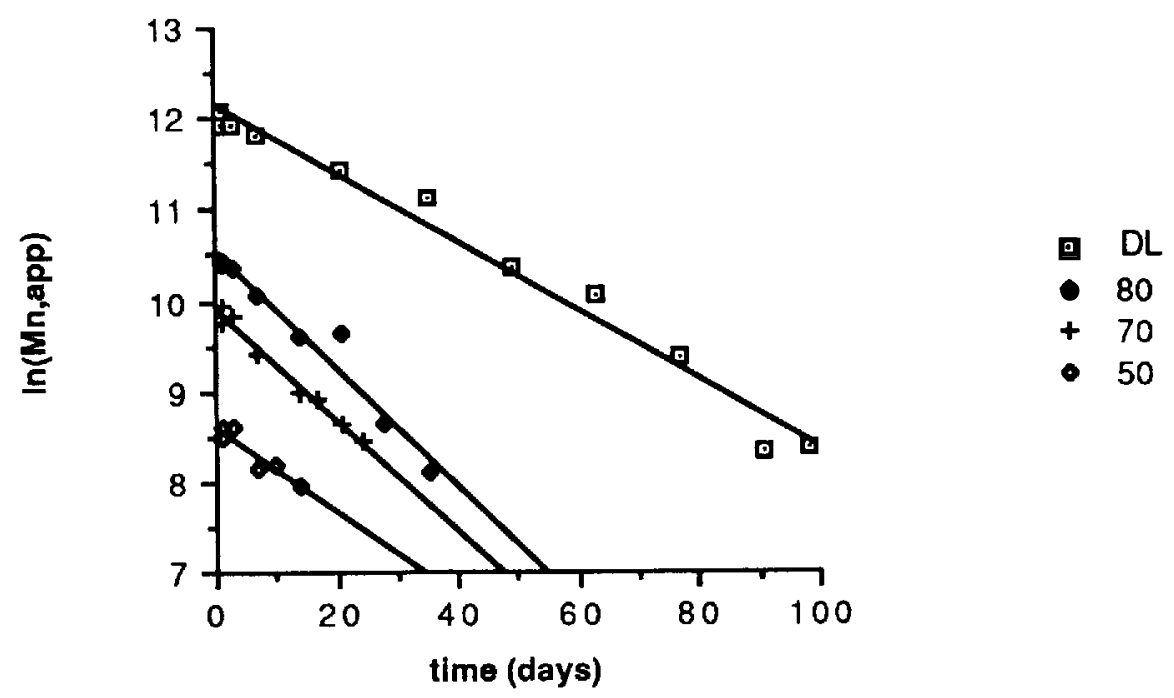

Figure 8. Plot of $\ln \left(M_{n, \text { app }}\right)$ as a function of immersion time (consistent with Eq. (2)) for (co)polymers 50, 70, 80, and DL.

The GPC patterns of (co)polymers 90,100 and DL became bimodal just before the start of weight loss (Fig. 4). Recently Ming et al. ${ }^{30}$ reported that the GPC patterns of polymer plates of glycolic/L-lactic acid copolymers and PLLA also became bimodal after several weeks in vitro degradation. The molecular weight of the central part of the plates were much lower than at the surface. These authors assigned this feature to the fact that the degradation is acid-catalyzed and controlled by ion-exchange at the surface. Acidic

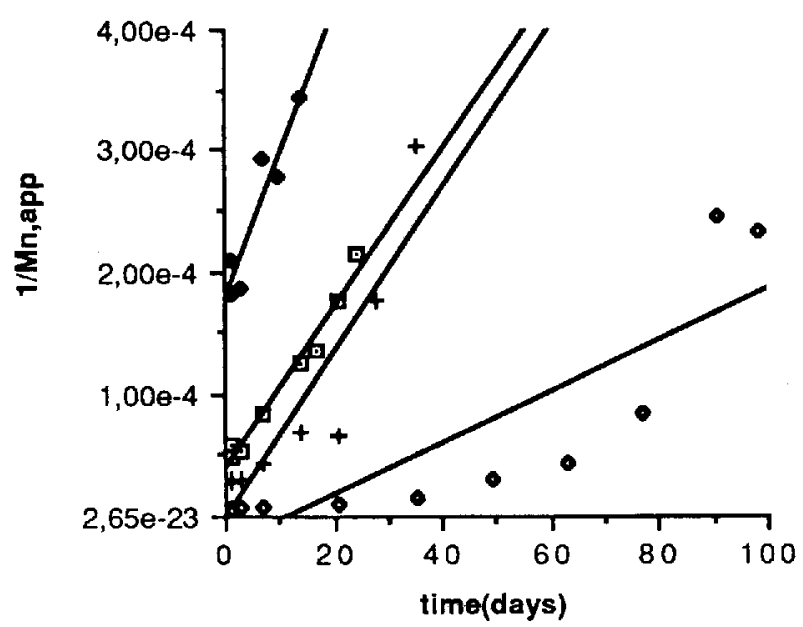

Figure 9. Plot of $1 / M_{n, \text { app }}$ as a function of immersion time (consistent with Eq. (4)) for (co)polymers 50, 70, 80, and DL. 
TABLE III

Slopes and Correlation Coefficients of the Plots of $\ln \left(M_{n, \text { app }}\right)$ and $1 / M_{n, \text { app }}$ vs. Time Consistent with Eq. (2) and (4), Respectively

\begin{tabular}{rccccc}
\hline & \multicolumn{2}{c}{ Autocatalytic Hydrolysis } & & \multicolumn{2}{c}{ Uncatalyzed Hydrolysis } \\
\cline { 2 - 3 } Code & Slope $=k_{2}\left(\times 10^{2}\right.$, day $\left.^{-1}\right)$ & $r$ & & Slope $=k_{4}\left(\times 10^{-6}\right.$, day $\left.^{-1}\right)$ & $r$ \\
\hline 50 & 5 & 0.93 & 12 & 0.94 \\
60 & 7 & 0.98 & 9 & 0.98 \\
70 & 6 & 0.99 & 7 & 0.99 \\
75 & 5 & 0.99 & 4 & 0.96 \\
80 & 7 & 0.98 & 7 & 0.90 \\
90 & 5 & 0.98 & 6 & 0.90 \\
100 & 5 & 0.99 & 2 & 0.86 \\
DL & 4 & 0.99 & & & \\
\hline
\end{tabular}

polymeric fragments, which are formed inside the polymer mass cannot escape before their molecular weight and solubility become such that soluble low-molecular-weight species can diffuse to the aqueous surrounding medium. This may also explain the bimodal GPC pattern of the films of (co)polymers 90, 100, and DL, which have a dense inner structure (Fig. 6). The transport of the acidic polymeric fragments to the surrounding medium is more facile in the glycine/DL-lactic acid copolymers, which contain voids (Fig. 5) and show an increasing porosity during the degradation (Fig. 7).

The weight loss during the first few days is probably due to loss of residual solvent (THF), which is still present even after the extensive drying procedure ${ }^{27}$ The presence of residual solvent was confirmed by NMR spectroscopy. The retention of a few percent of solvent is a general feature for solvent-cast polymer films. The only way of eliminating retained solvent is heating the polymer films above the melting point. ${ }^{31}$

Although the hydrolysis constants and initial molecular weights are comparable for the different copolymers, weight loss was found to occur sooner for copolymers with a higher content of glycine units (Fig. 1). This can be explained by the higher solubility of the fractions rich in glycine residues, which have a more hydrophylic character as compared to fractions containing a low percentage of glycine units. Further evidence was obtained from the NMR analysis of the composition of partly degraded copolymers (Table II) showing that residual material contains relatively more DL-lactic acid, which is caused by early dissolution of low molecular weight fractions rich in glycine units.

The rate of weight loss for different (co)polymers appears to be dependent on the composition and shows a minimum for copolymers containing a mol fraction of DL-lactide units of 0.7-0.8 (Fig. 2). The differences in the rates of dissolution of the (co)polymers can be explained as follows. In the course of the degradation of polymers 100 and DL, the molecular weight distributions gradually shift to lower molecular weights. Apparently at this stage a few more chain scissions are sufficient to solubilize all the material. Copoly- 
mer 90 containing less that $5 \%$ glycine units shows a degradation behavior very similar to PDLA. For copolymers 75 and 80 the low-molecular-weight fractions rich in glycine units become much earlier soluble than the fractions rich in lactic acid units due to the higher solubility of the glycine rich fractions. For the copolymers containing a higher percentage of glycine residues than copolymers 75 and 80 the differences in composition in the fractions will be less pronounced.

\section{CONCLUSIONS}

The in vitro degradation of glycine/DL-lactic acid copolymers and poly(DLlactic acid) is best described by hydrolysis, autocatalyzed by the generated carboxylic end groups. It was shown that the hydrolysis rate constants are in the same order of magnitude. This implies that only ester bond scission occurs and that the rate of hydrolysis is not significantly influenced by the composition of the copolymer. Copolymers containing a high glycine content show weight loss at an earlier stage than copolymers with a low glycine content. After the start of weight loss; the lactic acid content in the remaining material increases in time indicating early dissolution of fragments rich in glycine residues. The rate of weight loss shows a minimum for copolymers containing $20-25 \%$ (Gly-DL-Lac) residues. The differences in degradation times must be ascribed to the higher solubility of the fractions rich in glycine units.

\section{References}

1. M. Vert, "Bioresorbable polymers for temporary therapeutic applications," Angew. Macromol. Chem., 166/167, 155-168 (1989).

2. S. J. Holland, B. J. Tighe, and P. L. Gould, "Polymers for biodegradable medical devices. 1 . The potential of polyesters as controlled macromolecular release systems," I. Controlled Rel., 4, 155-180 (1986).

3. J. Heller, "Biodegradable polymers in controlled drug delivery," $C R C$ Crit. Rev. Ther. Drug Carrier Syst., 1, 39-90 (1984).

4. D. L. Wise, T. D. Fellmann, J. E. Sanderson, and R. L. Wentworth, "Lactic/glycolic acid polymers," in Drug Carriers in Biology and Medicine, G. Gregoriadis (ed.), Academic Press, New York, 1979, pp. 237-270.

5. S. W. Kim, R. V. Petersen, and I. Feijen, "Polymeric drug delivery systems," in Drug Design, Vol. 10, E. J. Ariens (ed.), Vol. 10, Academic Press, New York, 1980, pp. 193-250.

6. A.M. Reed and D.K. Gilding, "Biodegradable polymers for use in surgery-poly(glycolic)/poly(lactic acid) homo- and copolymers: 2 . In vitro degradation," Polymer, 22, 494-498 (1981).

7. R.M. Ginde and R.K. Gupta, "In vitro chemical degradation of poly(glycolic acid) pellets and fibers," ). Appl. Polym. Sci., 33, 2411-2429 (1987).

8. J. W. Leenslag, A. J. Pennings, R. R. M. Bos, F. R. Rozema, and G. Boering, "Resorbable materials of poly(L-lactide). In vivo and in vitro degradation," Biomaterials, 8, 311-317 (1987).

9. C. G. Pitt and Z. Gu, "Modification of the rates of chain cleavage of poly(e-caprolactone) and related polyesters in the solid state, ${ }^{\prime \prime} J$. Controlled Rel., 4, 283-292 (1987). 
10. R. A. Kenley, M. O. Lee, T. R. Mahoney, and L. M. Sanders, "Poly(lactideco glycolide) decomposition kinetics in vivo and in vitro," Macromolecules, 20, 2398-2403 (1987).

11. C. C. Chu, "Degradation phenomena of two linear aliphatic polyester fibres used in medicine and surgery," Polymer, 26, 591-594 (1985).

12. C. C. Chu and N.D. Campbell, "Scanning electron microscopic study of the hydrolytic degradation of poly(glycolic acid) suture," J. Biomed. Mater. Res., 16, 417-430 (1982).

13. N.S. Mason, C. S. Miles, and R. E. Sparks, "Hydrolytic degradation of poly DL-(lactide)," in Biomedical and Dental Applications of Polymers, Gebelein and Koblitz (eds.), Plenum Press, New York, 1981, 279.

14. C. G. Pitt, M. M. Gratzl, G. L. Kimmel, J. Surles, and A. Schindler, "Aliphatic polyesters II. The degradation of poly(DL-lactide, poly( $\varepsilon$ caprolacton) and their copolymers in vivo," Biomaterials, 2, 215-220 (1981).

15. R. A. Miller, J. M. Brady, and D. E. Cutright, "Degradation rates of oral resorbable implants (polylactates and polyglycolates): Rate modification with changes in PLA/PGA copolymer ratios," J. Biomed. Mater. Res., 11, 711 (1977).

16. D. F. Williams and E. Mort, "Enzyme-accelerated hydrolysis of polyglycolic acid," I. Bioeng., 1, 231-238 (1977).

17. D. F. Williams, "Enzymatic hydrolysis of polylactic acid," Eng. Med., 10, 5-7 (1981).

18. C. G. Pitt, R. W. Hendren, A. Schindler, and S. C. Woodward, "The enzymatic surface erosion of aliphatic polyesters," I. Controlled Rel., 1, 314 (1984).

19. T. N. Salthouse, "Cellular enzyme activity at the polymer-tissue interface: A review," J. Biomed. Mater. Res., 10, 197-229 (1976).

20. R. D. Gilbert, V. Stannett, C. G. Pitt, and A. Schindler, "The design of biodegradable polymers: two approaches," in Development in Polymer Degradation, Vol. 4, N. Grassie (ed.), Applied Science Publishers, London, 1982, pp. 259-293.

21. S. C. Woodward, P. S. Brewer, F. Moatamed, A. Schindler, and C. G. Pitt, "The intracellular degradation of poly(e-caprolactone)," J. Biomed. Mater. Res., 19, 437-444 (1985).

22. Y. Tokiwa, T. Suzuki, and T. Ando, "Synthesis of copolyamide-esters and some aspects involved in their hydrolysis by lipase," I. Appl. Polym. Sci., 24, 1701-1711 (1979).

23. T. H. Barrows, J. D. Johnson, S. J. Gibson, and D. M. Grussing, "Polymers in medicine 2," in Polymer Science and Technology, Plenum, New York, 1986, p. 85.

24. M. Asano, M. Yoshida, I. Kaetsu, R. Katakai, K. Imai, T. Mashimo, H. Yuasa, H. Yamanaka, and K. Suzuki, "Study of biodegradability of (AlaAlaGlu(OEt)Lac)n as a polydepsipeptide," J. Jpn. Soc. Biomater, , 3, 85-94 (1985).

25. M. Asano, M. Yoshida, I. Kaetsu, R. Katakai, K. Imai, T. Mashimo, $H$. Yuasa, and H. Yamanaka, "In vivo degradation of sequential polymers consisting of three amino acid moieties and one hydroxy moiety such as Ala- $X$-Glu(OEt)-Lac ( $X=G l u, A l a$, and Leu) as amino acid moiety) and Ala-Ala-Glu(OEt)-Y ( $\mathrm{Y}=$ Hea, Lac, and Hmp as hydroxy acid moieties), Polydepsipeptides 2," Seitai Zairyo, 4, 65-75 (1986).

26. I. Kaetsu, M. Yoshida, M. Asano, H. Yamanaka, K. Imai, H. Yuasa, T. Mashimo, K. Suzuki, R. Katakai, and M. Oya, "Biodegradable implant composites for local therapy." J. Controlled Rel., 6, 249-263 (1986).

27. J. M. Schakenraad, P. Nieuwenhuis, I. Molenaar, J. Helder, P. J. Dijkstra, and J. Feijen, "In vivo and in vitro degradation of glycine/DL-lactic acid copolymers," J. Biomed. Mater. Res., 23, 1271-1288 (1989). 
28. J. Helder, J. Feijen, S. J. Lee, and S. W. Kim, "Copolymers of D,L-lactic acid and glycine," Makromol. Chem., Rapid Commun., 7, 193-196 (1986).

29. M. Inokuti, "Weight-average and $z$-average degree of polymerization for polymers undergoing random scission," J. Chem. Phys., 38, 11741178 (1963).

30. L. S. Ming, H. Garreau, and M. Vert, Preprints Kunming International Symposium on Polymeric Biomaterials, May 3-7, 1988.

31. A.K. Doolittle, in The Technology of Solvents and Plasticizers, Wiley, New York/London, 1954, p. 240.

Received September 13, 1989

Accepted January 23, 1990 